\title{
Broad-Scale Land Condition Monitoring using Landsat TM and DEM-Derived Data
}

\author{
Fiona Evans ${ }^{1}$, Adrian Allen ${ }^{2}$, Peter Caccetta ${ }^{1}$ Suzanne Furby ${ }^{1}$ and Jeremy \\ Wallace ${ }^{1}$ \\ ${ }^{I}$ CSIRO Mathematical and Information Sciences \\ 'WA Department of Land Administration
}

Key words: Remote Sensing, DEM, Salinity Monitoring

Abstract: We describe a project that is monitoring land condition in the south west of Western Australia using Landsat Thematric Mapper satellite images and terrain data derived from digital elevation models (DEMs). Land Monitor is a multi-agency project of the Western Australian Salinity Action Plan supported by the Natural Heritage Trust. The focus of the project is on broad-scale monitoring of land condition for environmental mangement at both catchment and policy levels. Land Monitor will provide land managers and administrators with baseline salinity and vegetation data for monitoring changes over time, and accurate land height data. Land Monitor will cover the 18 million hectares of agricultural land of south west Western Australia. Sequences of calibrated Landsat Thematic Mapper satellite images integrated with landform information derived from height data, ground truthing and other existing mapped data sets are used as the basis for monitoring changes in salinity and woody vegetation. Heights are derived on a $10 \mathrm{~m}$ grid from stereo aerial photography flown at 1:40,000 scale, using soft-copy automatic terrain extraction techniques. Land Monitor products will include salinity maps, enhanced imagery, vegetation status maps and spectral / temporal statistics. These products will be available in a range of formats and scales, from paddock, farm to catchment and regional scales.

\section{INTRODUCTION}

Land salinisation, salinisation of inland waters and maintaining biodiversity have been identified as the three highest priority environmental issues in Western Australia (Western Australian State of Environment

The original version of this chapter was revised: The copyright line was incorrect. This has been corrected. The Erratum to this chapter is available at DOI: 10.1007/978-0-387-35503-0_29 
Report, 1998). However, government agencies and landholders have grossly underestimated the extent of salt-affected land in the agricultural areas of Western Australia (Ferdowsian et al., 1996). The effect of salinity on the extent and condition of native vegetation in the south-west has not been accurately assessed. In late 1996, the WA Salinity Action Plan was released stating that over $70 \%$ of Australia's dryland salinity could be found in WA. About 1.8 million ha in WA are already salt-affected, and this area could double in the next 15 to 25 years and then double again before reaching equilibrium.

The Land Monitor project is a three-year (1998, 1999 and 2000) collaborative project which aims to provide information to land managers on the area of salt-affected land and perennial vegetation cover, and their change through time. The project partners include CSIRO Mathematical and Information Sciences (CMIS), Agriculture WA, Department of Land Administration, Water and Rivers Commission, Department of Environmental Protection, Department of Conservation and Land Management, and Main Roads WA.

The project places into operation methods developed as part of a series of pilot projects funded by the Land and Water Resources Research and Development Corporation (references). The results of the pilot projects have shown that Landsat TM satellite images provide an inexpensive means for mapping land condition over broad areas. The pilot projects have examined a number of environmental issues including salinity, waterlogging, wind erosion, rangeland condition, forest condition and cereal crop yield monitoring.

The approach taken in each of these projects was for CMIS to work in collaboration with WA state agencies to develop and apply methods for broad-scale land condition monitoring. The support of agencies and catchment groups has had important consequences on the use of the final maps for on-ground and policy-level use. Involvement is promoted at three levels: at the beginning of the project (ground data collection, identification of datasets, refinement of models), during the project (on-ground validation of intermediate products) and at the final stage (on-ground validation of the final products). This process raises awareness about the projects amongst possible end-users and promotes ownership of the project results and confidence in the final maps.

\section{THE STUDY AREA}

The south-west agricultural region of WA is covered by 15 Landsat TM scenes. The map below shows the extent of the study area. Agency representatives and catchment groups throughout the study area are involved 
in the collection of ground truth data. Data were provided in the form of farm-plans, areas marked on maps and image interpretations. An example is shown below. The ground truth sites were examined in each of the Landsat images to determine the ground cover for each date. Approximately half of the sites are selected randomly and retained for validation of the output maps.

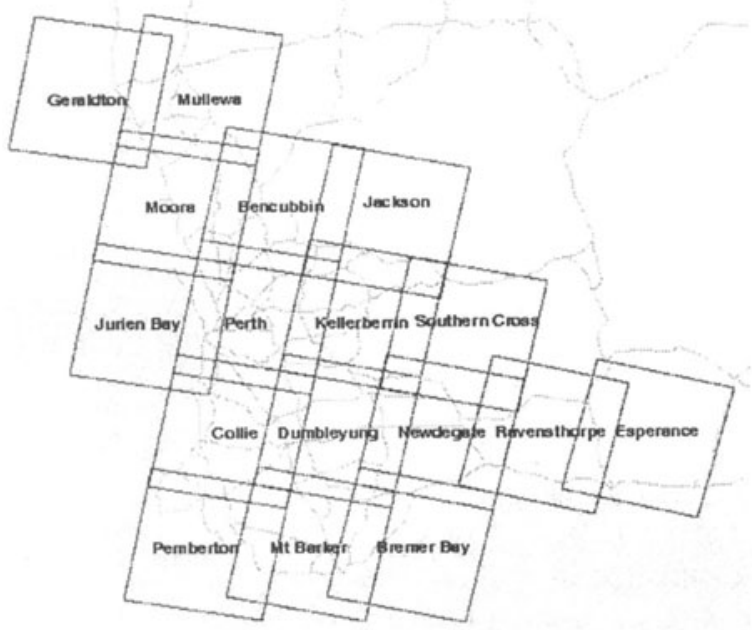

Figure 1. Landmonitor Study Area - South West WA

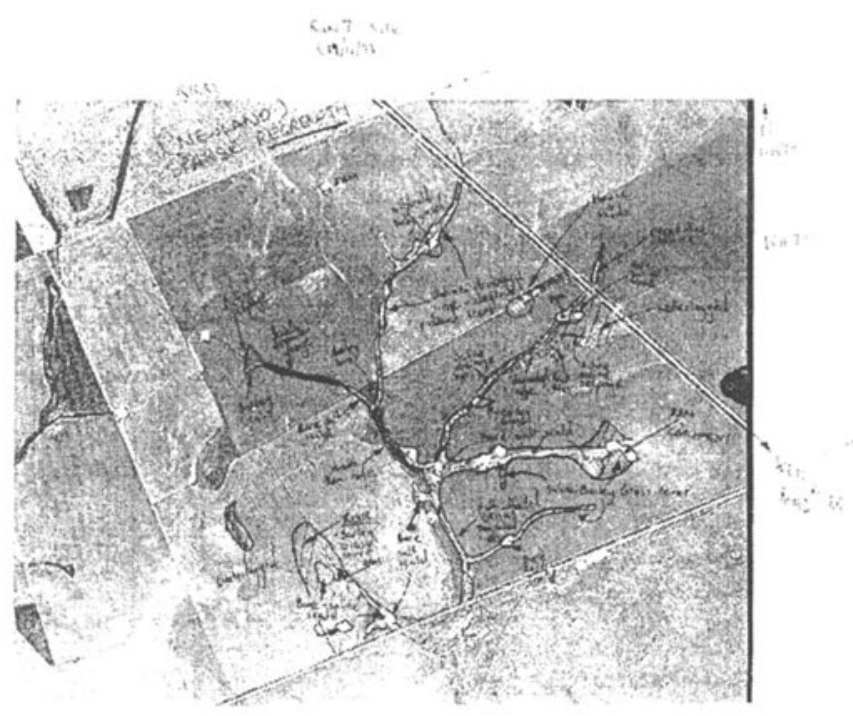

Figure 2. Ground Data for Salinity Monitoring 
Spring Landsat TM images are acquired so that crops and pastures are captured at the time of maximum growth and be most easily distinguished from areas affected by salinity. Summary Landsat TM images are acquired so that remnant vegetation and forest condition can be assessed when seasonal grasses are dormant.

To enable multi-temporal analyses of Landsat TM data, it is important that the images are accurately registered and calibrated, so that for any geolocated pixel, each image in the multi-temporal sequence shows the ground location and measures the same radiometric values for the same physical attributes. Image registration is described by Richards (1986, pp. 50-63). Cross-correlation techniques are be used to aid the selection of ground targets for registration.

Image calibration is required to enable comparisons of the digital data from different dates and multi-temporal analysis of the data. Calibration to 'like-values' (Furby et al., 1997) relies on the selection of ground targets which are spectrally invariant through time (such as deep water, bare sands and gravel pits). Robust regression techniques, in particular the S-estimation technique described by Rousseeuw and Leroy (1984), are used to produce the calibrated images, so that targets that show spectral changes through time (eg. shifting patterns of sand and shadow in bare sand targets) are downweighted in the regression analysis. The satellite images are co-registered to AMG coordinates at $25 \mathrm{~m}$ pixel and calibrated to 'like-values'.

Figure 3 shows the water accumulation map corresponding to a section of the study area

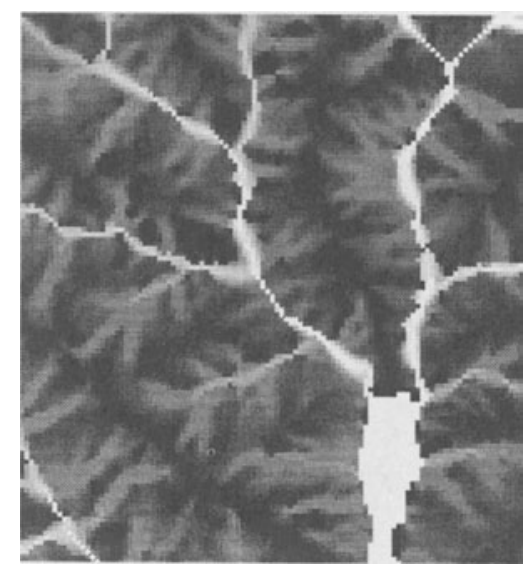

Figure 3. Water accumulation map - increasing values are shown from black to white. 


\section{MONITORING SALINITY}

The steps used to produce the salinity maps are listed below. This is the standard methodology being used for Land Monitor salinity mapping and monitoring. Co-register the images to a common map base. This allows ground sites to be traced through time and the satellite data to be compared with the ancillary map data, such as the DEM. Calibrate the image data from different dates to a reference image so that digital counts from different image dates can be compared (Furby et al., 1996).

Locate ground sites of all the major cover types in each of the images. Stratify the study area into zones within which there are no marked regional variations in rainfall, land-use types or rotations, geology, predominant soil types or visible patterns in the image. If there are strong differences between these zones, they are processed separately.

Apply discriminant analysis procedures, in particular canonical variate analyses (Campbell and Atchley, 1981), to the training data to examine the separation of ground cover types in the TM spectral data, determine which image dates are most appropriate and define sensible spectral groupings of ground cover types.

Apply maximum likelihood classification techniques to the best individual image dates. This produces probabilities of belonging to each of the major cover classes on each date for each pixel in the images.

Combine the cover class probabilities from each date with position in the landscape - hill, slope, valley floor - to calculate the probability of each pixel being salt-affected. A conditional probability network (CPN) is used for these calculations (Caccetta et al., 1995).

Post-processing to remove obvious errors in the final salinity maps, such as roads, edges of bush blocks, dams and some hilltops being labelled as salt-affected.

Canonical variate analysis provides a method for transforming input attribute data in such a way that the separation between training classes is maximised. Plots of canonical variate means for the training sites provide a simple tool for examining the separability of the classes.

Conditional probabilistic networks (CPNs), also called Bayesian networks and causal probabilistic networks, provide a framework for describing probabilistic relationships between a number of different variables. A CPN is a graphical model that describes the joint probability distribution for a number of variables via conditional independence assumptions and local probability distributions (Heckerman, 1996). The network structure of a conditional probabilistic network is a directed acyclic graph. The nodes in the graph correspond to the variables of interest. The edges joining nodes correspond to joint probability distributions between the 
variables represented by those nodes. More detail about graph theory and its application in CPNs can be found in Lauritzen and Spiegelhalter (1988) and Neapolitan (1990).

Given a set of variables $X=\left\{x_{b}, \ldots, x_{n}\right\}$, each with parents $P_{i}$, the joint probability distribution of $X$ is given by

$$
p(X)=\prod_{i=1}^{n} p\left(x_{i} \mid P_{i}\right) .
$$

The local probability distributions correspond to the conditional distributions in the product on the right hand side of the above equation. If the conditional distributions are known, then it is possible to calculate the joint probability distribution using Bayes' rule.

Construction of a conditional probabilistic network requires that the variables are ordered, and the relationships between variables are examined, so that conditional probability distributions can be defined for subsets of variables that are conditionally dependent. For example, Figure 4 shows a simple network which aims to map salinity using a two-year sequence of landcover maps produced from classified Landsat TM data (with associated accuracy statistics) and a landform map. In this graph, the square nodes represent the input attribute data $(y 1=$ landcover mapped in year $1, y 2=$ landcover mapped in year 2 and $l f=$ landform type), and the circular nodes represent the outputs $(s 1=$ salinity in year 1 and $s 2=$ salinity in year 2$)$.

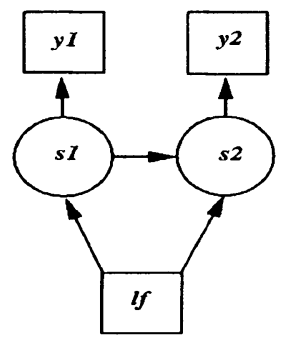

Figure 4

The network contains four cliques of child nodes and their parents: (lf, $s l),(l f, s 1, s 2),(s 1, y l)$ and $(s 2, y 2)$. This structure represents the following assumptions. The mapped landcover type depends on the true salinity status at any time.The salinity status for year 1 depends upon the landform type.The salinity status at year 2 depends on both landform and whether that area was salt-affected in the previous year. Conditional probability distributions must be defined for each of these cliques such that

$$
\mathrm{P}(X)=\mathrm{p}(s 1 \mid l f) \mathrm{p}(s 2 \mid l f, s 1) \mathrm{p}(y 1 \mid s 1) \mathrm{p}(y 2 \mid s 2) \mathrm{p}(l f) .
$$

The model can then be extended to include nodes corresponding to each of the images in a multi-temporal sequence. The conditional probability 
distributions can be supplied to the CPN in the form of tables. The probability tables are initialised using the error estimates from the maximum likelihood classifications and expert knowledge of the probabilities of different cover types occurring in each landform type. The expectationmaximisation algorithm (Dempster et al., 1977) can be used to estimate probabilities when expert knowledge is not available.
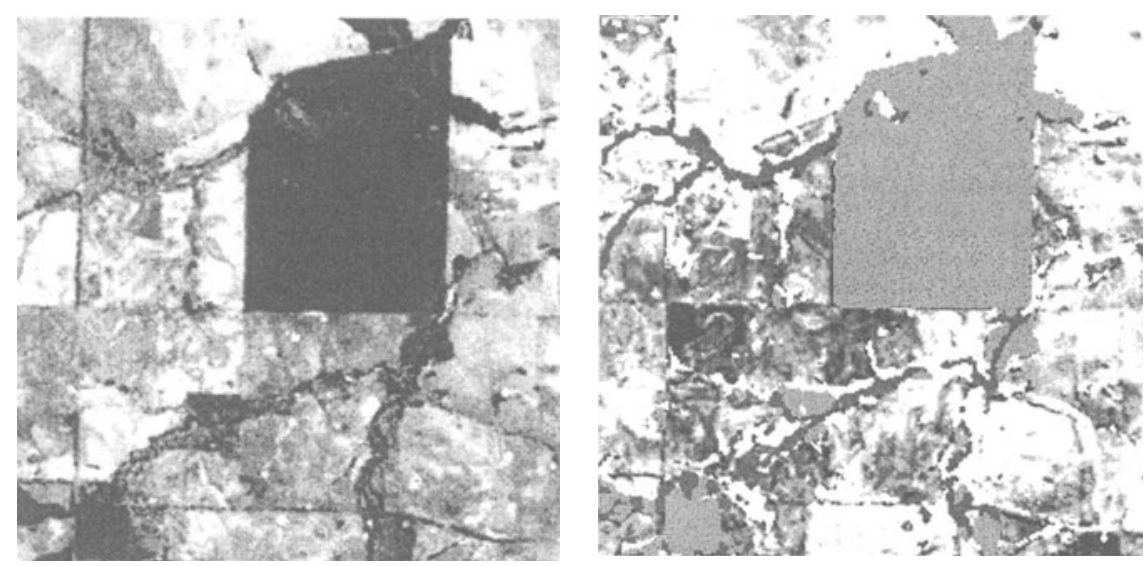

Figure 5. (i) Landsat TM image and (ii) corresponding salinity map - areas mapped as salt-affected (greyscale of red and yellow) have been mapped as being in poor condition for more than one growing season.

Maps are produced for the validation areas, and error estimates are calculated. The error estimates and visual assessment of the salinity maps are then used to refine the probability tables. This process is iterated until the accuracies are sufficiently high. Figure 5 shows an example of a salinity map produced using the conditional probabilistic network. In this map, severely salt-affected areas are shown in red and marginally salt-affected areas that support salt-tolerant species or show decreased yields are shown in yellow.

\section{MONITORING VEGETATION STATUS}

Two types of vegetation change maps are produced: maps of perennial / woody vegetation cover and change through time and maps indicating the degree of change during particular time periods. The former show broad cover changes such as clearing and regeneration. The latter are prepared in the absence of ground data; however, visual interpretation has proved useful for indicating areas of relatively stable cover over the given time period, and areas that have undergone some change in vegetation status, such as variations in rates of increase and decrease in vegetation cover due to 
plantations, regeneration from fire, and clearing for agricultural purposes and from fire. The steps involved are:

Co-register the images to a common map base. This allows ground sites to be traced through time and the satellite data to be compared with the ancillary map data, such as the DEM.

Calibrate the image data from different dates to a reference image so that digital counts from different image dates can be compared (Furby et al., 1996).

Locate ground sites of all the major cover types in each of the images.

Produce indices / band combinations and appropriate threshholds for discrimination of perennial / woody vegetation cover.

Combine time-sequences of images to produce change maps and show areas of increase in cover (such as plantations, regeneration and recovery from fire) and areas of decrease in cover (such as bush fires, disease or clearing).

\section{CASE STUDY}

The Fitzgerald Biosphere reserve is recognised as an area of international biodiversity significance. It is one of only two Biospheres in Australia. CSIRO Mathematical Sciences, in collaboration with Agriculture Western Australia and WA Conservation and Land Management are conducting a project that will develop an integrated vegetation management plan for the region. This project uses salinity and vegetation change maps to provide integrated management over the regional scale.

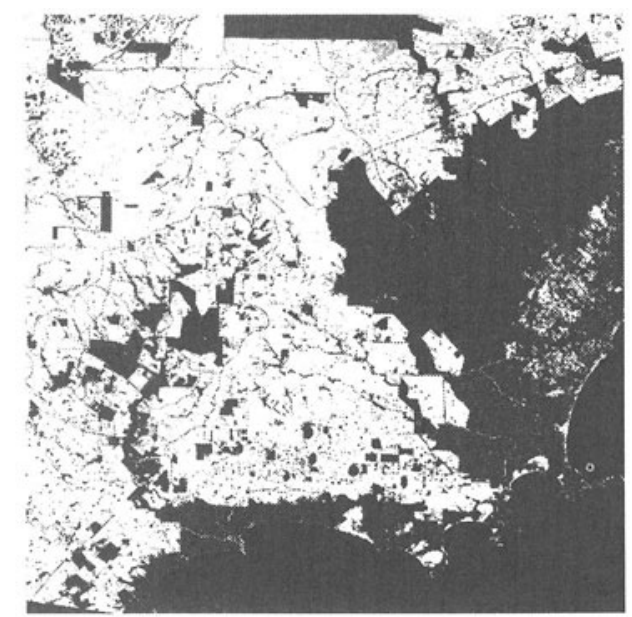

Figure 6 Greysacale rendering of Fitzgerald Biophere salinity map. 
Figures 6 and 7 show the salinity map and vegetation change map for part of the Biosphere. In Figure 7, the Fitzgerald River National Park can be seen the south east part of the maps, and the Lake Magenta Reserve is in the central northern part of the maps. Two catchment areas (and the subcatchments within them) are outlined in black; these correspond to the Pallinup River in the south west and the Fitzgerald River in the north east. The maps clearly show that the Fitzgerald River catchments have been extensively cleared and are experiencing severe loss of agricultural land to salinity and degradation to varying degrees of the remant vegetation that remains along streamlines. The bush corridor that follows the Fitzgerald River from the Laké Magenta Reserve to the National Park is becoming degraded, threatening the conservation of fauna that require free movement between the two reserves. The Pallinup River catchments, have been only partly cleared and have lost only limited amounts of land to salinity.

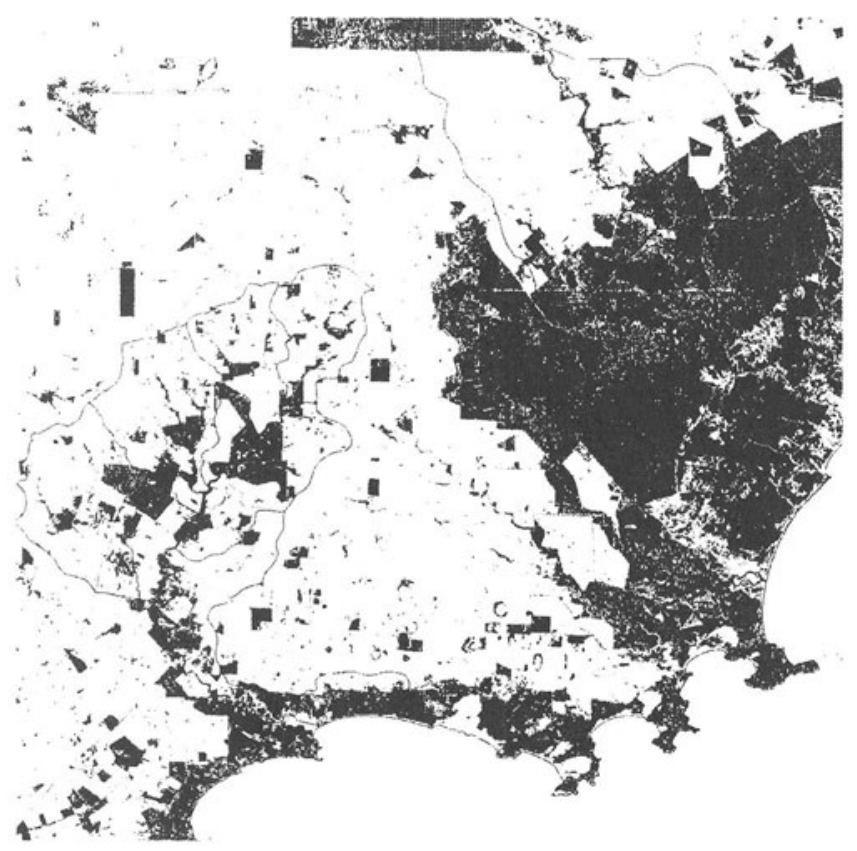

Figure 7 Fitzgerald Biosphere vegetation change map.

Australian landcare projects are funded by the National Heritage Trust according to the potential benefits of the project. Usually, projects are undertaken by individual farmers or catchment groups and there is little or no assessment of the regional effects of the project. In the Fitzgerald Biosphere, catchments with severe salinity problems like those of the Fitzgerald River are most active in gaining funding for landcare projects, 
such as fencing of remnants and revegetation of strategic areas. However, the bush corridor that follows the Pallinup River to the coastline is also valuable for conservation purposes, particularly because the condition of the bush reserves in this corridor remains stable. In the absence of serious degradation, the catchment groups in this area remain inactive and there is little funding being provided by on-ground work. In fact, some farmers are still clearing land in this area as can be clearly seen in Figure 8. This is a serious cause for concern when the issues are examined at the regional scale. Continued clearing combined with lack of interest in landcare is likely to cause future salinisation problems in this area, placing the bush reserves that are currently in good condition at risk from future degradation and putting a larger stress on fauna in the Fitzgerald Biosphere.

Regional land management in now aiming to help preserve areas of high conservation value that are presently in good condition as well as help ameliorate areas that are currently degraded.

\section{REFERENCES}

Caccetta, P. C. (1997), Remote Sensing, GIS and Bayesian Knowledge-based Methods for Monitoring Land Condition, PhD Thesis Computer Science Curtin University, Australia.

Campbell, N. A. and Atchley, W. R. (1981), 'The geometry of canonical variate analysis', Syst. Zoology, Vol. 30, No. 3, pp. 268-280.

Dempster, A. P., Laird, N. and Rubin, D. B. (1977), 'Maximum likelihood from incomplete data via the EM algorithm', Journal of the Royal Statistical Society, Series B, Vol, 39, pp. $1-38$.

Evans, F. H. (1998), An investigation into the use of maximum likelihood classifiers, decision trees, neural networks and conditional probabilistic networks for mapping and predicting salinity, MSc thesis Computer Science, Curtin University, Australia.

Ferdowsian, R., George, R., Lewis, R., McFarlane, D. and Speed, R. (1996), 'The extent of dryland salinity in Western Australia', Proceedings of the 4th National Workshop on the Productive Use and Rehabilitation of Saline Lands, pp. 89-98.

Furby, S. L., Campbell, N. A. and Palmer, M. J. (1997), 'Calibrating images from different dates to like value digital counts', submitted to Remote Sensing of the Environment.

Furby, S. L. and Wallace, J. F. (1998), 'Land condition monitoring in the Fitzgerald Biosphere region', Proceedings of the 9th Australasian Remote Sensing Conference, available on CDROM.

Furby, S. L., Evans, F. H., Wallace, J. F. Ferdowsian, R. and Simons, J. (1998), Collecting ground truth data for salinity mapping and monitoring, Land Monitor task report.

Jensen, S. K. and Domingue, J. O. (1988), 'Extracting topographic structure from digital elevation data for geographic information system analysis', Photogrammetric Engineering and Remote Sensing, Vol. 54, No. 11, pp.1593-1600.

Lauritzen S. L. and Spiegelhalter D. J. (1988), 'Local computations with probabilities on graphical structures and their application to expert systems', Journal of the Royal Statistical Society, Vol. 50, No. 2, pp. 157-224.

Moore, I. D., Grayson, R. B. and Ladson, A. R. (1991), 'Digital terrain modelling: a review of hydrological, geomorphological and biological applications', Hydrological Processes, Vol. 5, No. 1, pp. 3-30. 
Neapolitan, R. E. (1990), Probabilistic reasoning in expert systems, John Wiley and Sons, USA.

O'Callaghan, J. F. and Mark, D. M. (1984), 'The extraction of drainage networks from digital elevation data', Computer Vision, Graphics and Image Processing, Vol. 28, pp. 323-344.

Quinn, P., Beven, K., Chevallier, P. and Planchon, O. (1991), 'The prediction of hillslope flow paths for distributed hydrological modelling using digital terrain models', Hydrological Processes, V5, \# 1, pp. 59-79.

Richards, J. A. (1986), Remote sensing digital image analysis: an introduction, SpringerVerlag, New York.

Rousseeuw, P. J. and Leroy, A. M. (1984), 'Robust regression by means of S-estimators', in Robust and Nonlinear Time Series Analysis, ed. Franke, J., Hardle, W. and Martin, R. D., Lecture Notes in Statistics, Springer-Verlag, pp. 256-272.

Schultz, G. A. (1994), 'Meso-scale modelling of runoff and water balances using remote sensing and other GIS data', Hydrological Sciences - Journal des Science Hydrologiques, Vol. 39, No. 2, pp. 121-142.

Wheaton, G., Wallace, J. F., McFarlane, D. and Campbell, N. A. (1992), 'Mapping saltaffected land in Western Australia', Proceedings of the 6th Australasian Remote Sensing Conference, Vol. 2, pp. 369-377.

Wheaton, G., Wallace, J. F., McFarlane, D., Campbell, N. A. and Caccetta, P. C. (1994), 'Mapping and monitoring salt-affected land in Western Australia', Proc. Resource Technology '94 Conference, pp. 531-543. 